University of Wollongong

Research Online

Faculty of Business - Papers (Archive)

Faculty of Business and Law

2013

Iron ore spot price volatility and change in forward pricing mechanism

Yiqun Ma

University of Wollongong, ym903@uowmail.edu.au

Follow this and additional works at: https://ro.uow.edu.au/buspapers

Part of the Business Commons

Research Online is the open access institutional repository for the University of Wollongong. For further information contact the UOW Library: research-pubs@uow.edu.au 


\title{
Iron ore spot price volatility and change in forward pricing mechanism
}

\begin{abstract}
To examine the impact of the change in forward pricing mechanism on the volatility of iron ore spot prices, we model the iron ore daily price of Platts IODEX from October 7, 2008 to September 21, 2012. The identified iron ore spot price tends to be less volatile after the introduction of quarterly pricing mechanism. Our main approaches are as follows: (i) to decompose the spot price of Platts IODEX into two subsamples and relate the result of the structural break to the date of the switch in the iron ore forward pricing mechanism; (ii) to apply the $\operatorname{EGARCH}(1,1)$ model to simultaneously capture the long memory and the asymmetric effect on the volatility of the iron ore spot price; and (iii) to delineate the news impact curve to further interpret the asymmetric effect.
\end{abstract}

Keywords

change, pricing, volatility, forward, mechanism, iron, price, spot, ore

Disciplines

Business

Publication Details

$\mathrm{Ma}, \mathrm{Y}$. (2013). Iron ore spot price volatility and change in forward pricing mechanism. Resources Policy, 38 (4), 621-627. 


\title{
Iron Ore Spot Price Volatility and Change in Forward Pricing Mechanism
}

\author{
Yiqun $\mathrm{Ma}^{\mathrm{a}, *}$ \\ ${ }^{a}$ School of Economics, Faculty of Business, University of Wollongong, Northfields Avenue, Wollongong, NSW, 2522, \\ Australia
}

\begin{abstract}
To examine the impact of the change in forward pricing mechanism on the volatility of iron ore spot prices, we model the iron ore daily price of Platts IODEX from October 7, 2008 to September 21, 2012. The identified iron ore spot price tends to be less volatile after the introduction of quarterly pricing mechanism. Our main approaches are as follows: (i) to decompose the spot price of Platts IODEX into two subsamples and relate the result of the structural break to the date of the switch in the iron ore forward pricing mechanism; (ii) to apply the EGARCH $(1,1)$ model to simultaneously capture the long memory and the asymmetric effect on the volatility of the iron ore spot price; and (iii) to delineate the news impact curve to further interpret the asymmetric effect.
\end{abstract}

Keywords:

JEL: C22, Q30

Iron Ore Price, Structural Break, Volatility Modelling

\section{Introduction}

High volatility of spot prices in the global iron ore market has been widely observed and reported by the press, especially following the global financial crisis. Sellers and buyers facing high volatility of iron ore spot prices are apt to be affected by the exposure to large risks in the economic activity. The economic instability may be severe in some countries, affecting iron ore trading partners (such as Australia, India, China and Japan). Moreover, concern about high volatility of iron ore spot prices appears to be compounded by the previous annual benchmark pricing mechanism (annual price).

The annual benchmark pricing mechanism ${ }^{1}$ in the global iron ore market lasted as long as thirty years until the end of 2009. After the global financial crisis, this annual price was criticized

\footnotetext{
*Tel.: +612 42000141

Email address: ym903@uowmail.edu . au (Yiqun Ma)

${ }^{1}$ The annual benchmark pricing mechanism requires long term negotiation between the bilateral representatives (up to six months). After the release of the agreed price, all market participants are bound to sell and buy at this price for the whole year.
} 
as rigid and failed to rapidly reflect market demand (Musacchio et al., 2010). The rigidity of the iron ore annual price may intensify the concern about volatility of spot prices. To mitigate the volatility of spot prices, in the first quarter of 2010, the two iron ore giants Vale and BHP Billiton (accounting for $40 \%$ of global exports) announced that the annual benchmark pricing mechanism was abandoned and was replaced by a quarterly pricing mechanism (quarterly price) (UNCTAD, 2010). More importantly, this quarterly price is primarily determined by the three-month average spot prices of Platts IODEX ${ }^{2}$. However, the effect of the new pricing mechanism on the volatility of the iron ore spot price remains to be empirically investigated.

Economic studies of price volatility and the change in pricing mechanism have primarily focused on the oil market. While it is not clear in the global iron ore market, the nature of price volatility in the oil market has been indicated in a number of empirical papers. In particular, papers to explain the link between the volatility of the iron ore spot prices and the change in the forward pricing mechanism are still sparse.

The goal of this study is to empirically test whether or not the change in the forward pricing mechanism has a significant impact on the volatility of the iron ore spot prices. To the best of our knowledge, this study is the first to use daily data to document volatility of the iron ore spot prices. Considering sudden changes in the iron ore spot price of Platts IODEX and its volatility, we used the algorithm of Inclan and Tiao (1994) (iterated cumulative sum of squares (ICSS)) to detect structural breaks. In terms of structural breaks, the most relevant date for the change in the iron ore forward pricing and consequently the two subsample periods were identified. Over the two subsample periods, the performance of unconditional variance was immediately obtained, and that of conditional variance may be accurately estimated by the EGARCH $(1,1)$ model. Furthermore, by the analysis of the long memory, the asymmetric effect ${ }^{3}$ and the news impact curve, the relationship between the volatility of the Platts IODEX and the change in the forward pricing mechanism was detected. The proposed econometric models may be useful for market participants and policy makers to study volatility of the iron ore spot prices and its corresponding pricing mechanism.

The study has some distinguishing features. (i) The test of the structural break is applicable for detection of the date of the sudden change in the volatility of the iron ore spot price, which may be triggered by the presence of the new forward pricing mechanism. (ii) Over the two subsample periods, the use of the EGARCH $(1,1)$ model seems to be appropriate to quantify the long memory and the asymmetric effect on the volatility of the iron ore spot price. (iii) The asymmetric effect on the volatility of the iron ore spot price is illustrated by the news impact curve.

This paper is organized sequentially as follows. Section 2 stresses the background of the global iron ore market and the iron ore prices. Section 3 briefly reviews related empirical literature. Section 4 outlines possible empirical models. Section 5 explores the results of empirical analysis. Section 6 concludes the paper.

\footnotetext{
${ }^{2}$ Platts IODEX was first published in Singapore in the late of 2008, and was globally recognized as the primary index of the iron ore spot price.

${ }^{3}$ The asymmetric effect refers to time series data, where an unexpected reduction in certain asset price by a negative shock may cause higher volatility than an unexpected increase by a positive shock at the same magnitude.
} 


\section{The Global Iron Ore Market and the Change in the Forward Pricing Mechanism}

This section presents an overview of the global iron ore market and the underlying reasons for the change in the forward pricing mechanism. In particular, the iron ore market structure and some striking changes in the global iron ore market are highlighted. The fundamental factors, including the asymmetric effect and the persistent effect on volatility of the iron ore spot prices, may help in forming the basis for further empirical test.

\subsection{The Global Iron Ore Market}

Iron ore is a raw material for producing pig iron, which can then be transformed into steel. Steel is produced from three types of iron ore: fines, lumps and pellets. Among them, fines account for the majority of the exported iron ore due to the low cost in processing. As the primary input of steel making, iron ore is a fairly homogeneous product with limited substitutes (Convey, 2012). The production of iron ore is capital intensive and requires massive investment in the mining project and infrastructure. In addition, the bulk of ore is delivered by the seaborne market which is acknowledged as the iron ore supply market.

In the iron ore supply market, major sellers and exporters are Vale (formerly CVRD) in Brazil, Rio Tinto in Australia, BHP Billiton in Australia ("Big Three"). The market shares of the "Big Three" were prominent, with Vale accounting for 25.6\%, Rio Tinto 19.8\% and BHP Billiton 14.6\% in 2010 (UNCTAD, 2010). In 2011, the rise of their revenues in the iron ore sales (around $\$ 70$ billion) was primarily sourced from the increasing iron ore spot prices (Convey, 2012). Indeed, the iron ore supply market is characterized by the high market concentration.

The demand for iron ore is primarily driven by the production of steel. On the demand side, the outputs of the four largest steel makers in 2010 were modest, with Arcelor Mittal in Europe accounting for 6.4\%, Baosteel in China 3\%, POSCO in Korea 3\% and Nippon Steel in Japan $2 \%$ (UNCTAD, 2010). Since 2005, the Chinese buyers have been the largest consumers of iron ore, due to the rapid growth of the Chinese resource-intensive economy. Compared to the supply market, the iron ore demand market is far less concentrated.

\subsection{The Change in the Forward Pricing Mechanism and Possible Reasons}

In the first quarter of 2010, Vale and BHP Billiton announced a new quarterly pricing mechanism, which is primarily determined by the three-month average spot prices of Platts IODEX, to replace the role of annual price. As indicated, the purpose of the new pricing mechanism is to reduce the risk of the high volatility of the iron ore spot prices. However, this change may also lie in some non-trivial shifts in the global iron ore market.

\subsubsection{The Shift in Iron Ore Supply and Demand}

There have been some radical changes in the iron ore supply and demand market. The structure of iron ore demand and supply remained stable from the 1990s to the beginning of the 2000s. Since 2003, China has surpassed Japan as the world largest importer of iron ore due to growth in Chinese urbanization and industrialization. At the same time, owing to the slow response in production, the growth of the iron ore supply seemed not to be in line with the rapid rise in demand. As a result, the period of 2003-2008 was characterized by a steep increase in the iron 
ore spot prices (UNCTAD, 2010). The recorded high of the iron ore spot price was US\$180/t in 2009 (Platts, 2012). After 2009, the steel industry experienced the worst demand downturn, caused by the global financial crisis. Accordingly, the delayed adjustment to production may lead to the oversupply of iron ore, with the new production capacity accounting for 430Mt in 2009 (UNCTAD, 2010). Correspondingly, the iron ore spot price fluctuated in a region of US\$100$140 / t$ after 2009. It is worth stressing that the negative demand shock in the global iron ore market may cause higher price volatility than the positive demand shock.

\subsubsection{The Shift in the Iron Ore Prices}

The spot price, especially for the Platts IODEX, has been of growing importance in international iron ore transactions. Before 2009, the vast majority of iron ore was traded at the annual price, while the remaining was settled at the spot prices. The previous annual pricing mechanism required long term negotiation (up to six months) between the bilateral representatives in order to formulate the benchmark price for the next annual trading period (Crowson et al., 2006). The annual price continued for almost thirty years until the end of 2009. In 2009, BHP Billiton and Rio Tinto sold almost half of their outputs at the spot prices (Musacchio et al., 2010). The iron ore spot prices are determined through the real time interaction between sellers and buyers. Although there is more than one international spot price, the Platts IODEX since 2008 has been widely recognized by the "Big Three" as the main iron ore spot price.

After 2009, both iron ore sellers and buyers were subject to the spot prices with long term volatility, which was magnified by the fixed annual price. As publicly criticized, the annual price may not reflect market demand in a timely manner (Bhattacharyya and Deepak, 2012). As a consequence, the disparity between annual price and spot price was wide. Instead, in a transparent trading system the iron ore spot prices provide more instant demand information to the sellers and buyers.

\subsubsection{The Shift in the Purchasing Power of the Chinese Buyers}

The growing Chinese purchasing power of iron ore may challenge the iron ore price determination. Although China has an excessive demand for iron ore, the fragmented market shares of the Chinese steel companies weaken their position in price bargaining. In fact, from 2000 to 2008, nearly all the annual price negotiations ended up with price increases of more than $10 \%$ (Wilson, 2012). These results led to cost pressures for the Chinese buyers, while there were unprecedented profits for the "Big Three". However, the slump in iron ore demand after the global financial crisis may underpin the purchasing power of the Chinese buyers. In the 2009 annual price negotiation, China rejected the proposal of a $33 \%$ price cut from the "Big Three", and insisted on a $45 \%$ reduction (Musacchio et al., 2010). This request was accompanied by the default of the Chinese buyers on the annual price contracts and their switch to the spot transactions for the cheaper prices. To regain market power, the "Big Three" abandoned the annual price and implemented the spot-based quarterly price. Indeed, the Chinese buyers may benefit from the switch to the spot transactions in the short term, while it remains to be questioned in the long run.

To sum up, the "Big Three" gained the dominant market share in the global iron ore market. Simultaneously, the introduction of the quarterly price seemed to be designed to reduce the volatility of the iron ore spot prices and was driven by several changes in the global iron ore market. How- 
ever, the effect on price volatility of the switch in the iron ore forward pricing remains to be tested by the subsequent empirical approaches.

\section{Literature Review}

The extended generalized autoregressive conditional heteroscedasticity (GARCH) model has been widely used to measure price volatility in the empirical papers (Engle, 1983; Bollerslev, 1986; Caporale and McKiernan, 1997). Most papers are interested in finding the most appropriate model to fit and to forecast price volatility in the full sample period. Our study aims to examine the impact of the change in pricing mechanism on the volatility of the iron ore spot price over the different subsample periods. In this sense, the estimation of price volatility by the extended GARCH model and the test of the structural break were pursued.

Narayan and Narayan (2007) examined the feature of oil price volatility by the EGARCH model over the different subsample periods. As embodied by the EGARCH model in their paper, shocks have asymmetric effects on oil price volatility. In addition, their finding suggests that price volatility tends to significantly fluctuate over the different subsample periods. However, in their paper, the practical or economic reason for the selection of each subsample is not clear.

Hammoudeh and Yuan (2008) used a variety of extended GARCH models to estimate the price volatility in three commodities (gold, silver and copper) under the crude oil shocks and the interest rate shocks. In particular, they argue that shocks do not have equally asymmetric effects on commodity price volatility, as demonstrated proved by the news impact curve. Moreover, they claim that sudden changes in price volatility may be trigged not only by macroeconomic events, but also by internal issues such as pricing change, and technological advance.

Arouri et al. (2011) conducted a nonlinear GARCH model (FIGARCH) to investigate the relationship between the structural breaks and the long memory of shocks, and to forecast the conditional variance of the oil spot and futures prices. In their model, the adjusted method of the iterated cumulative sum of squares (ICSS) (Inclan and Tiao, 1994) was introduced to gauge the dates of structural breaks. Their results demonstrate that the nonlinear GARCH model associated with the structural break are the best fit models to forecast price volatility.

Given the hypothesis of non-stationarity in the selected data, Salisu and Fasanya (2012) adopted various GARCH models to analyze the conditional variance of oil price. The non-stationary effect is confirmed by the unit root test in Narayan and Popp (2010), which allows for two structural breaks in the data period. Apart from discovering the dates of structural breaks in the oil price, Salisu and Fasanya (2012) also tested the long memory and asymmetric effect on oil price volatility. In their paper, the EGARCH model performs better than other GARCH models for measuring price volatility.

In summary, most papers support that the extended GARCH model as providing the best fit model to estimate price volatility. Notably, the test of the structural break is appropriate to test the date of the sudden change in price volatility which may be driven by pricing change. Furthermore, the behaviors of price volatility may be analyzed by the added test, namely the long memory and the asymmetric effect, and the analysis of the news impact curve. 


\section{Empirical Method}

We used a two-step empirical procedure to examine the impact of the change in the forward pricing mechanism on the volatility of the iron ore spot price. Firstly, a return of the daily iron ore spot price was collected, and was split into two subsamples after the test of the structural break. Secondly, the EGARCH $(1,1)$ model was adopted to measure the volatility of the iron ore spot price return in the subsamples. In terms of the two subsamples, the performances of the EGARCH $(1,1)$ models were comprehensively compared and analyzed.

\subsection{Data and Structural Breaks}

In this study, the return of the iron ore spot price was computed as follows:

$$
r_{t}=\ln \left(P_{t}\right)-\ln \left(P_{t-1}\right)
$$

Where $P_{t}$ denotes the iron ore spot price and $r_{t}$ is the return of the spot price. The algorithm of first price difference may provide evidence of stationarity in the data series, and may take the role of target price.

Testing the structural breaks in the volatility of the iron ore spot price is one of the objectives of this study. The observed large changes in the return of the iron ore spot price and its volatility between 2008 and 2012 (Figure 1) may correspond to a range of structural breaks. The presence of structural breaks in the return of the iron ore spot price and its volatility needed to be empirically tested to determine if the change in the forward pricing has an effect on the volatility of spot price. Notably, due to the lag effect of a structural break on price volatility, the date of the change in the iron ore forward pricing may be not consistent with the specific break date in price volatility (Arouri et al., 2011). In this regard, the application of the ICSS (iterative cumulative sum of squares) seems to be useful for discovering the date of the structural break in the volatility of the iron ore spot price return.

As presented by Inclan and Tiao (1994), the variance of observed data is assumed to be stationary until a sudden change occurs. After this change, the variance is then stationary again until the next sudden change. This process may repeat over the whole data period $T$, given a number of $N$ breaks in the unconditional variance of observed data. This process is displayed as follows:

$$
\sigma_{t}^{2}=\left\{\begin{array}{c}
\tau_{0}^{2}, \quad 1 \leq t<\kappa_{1} \\
\tau_{1}^{2}, \quad \kappa_{1} \leq t<\kappa_{2} \\
\ldots \quad \kappa_{N} \leq t<T \\
\left.\tau_{N}^{2}, \quad \kappa^{2}\right)
\end{array}\right.
$$

To estimate the number of changes in variance and the given time of variance shift, a cumulative sum of squares is employed. $C_{k}=\sum_{t=1}^{k} \epsilon_{t}^{2}, k=1,2, \ldots T$, where $\epsilon_{t} \sim\left(0, \sigma_{t}^{2}\right)$ is a white noise as the equation (2). Then the following statistic is defined:

$$
D_{k}=\frac{C_{k}}{C_{t}}-\frac{k}{T}, \quad k=1, \ldots, T, \quad D_{0}=D_{t}=0 .
$$

The statistic $D_{k}$ oscillates around zero, given there are no changes in variance over the whole period. Instead, $D_{k}$ will move upward or downward from zero as one or more sudden changes are 
detected in the period. Under the algorithm of the ICSS, the results of structural breaks in the iron ore spot price will be derived. Accordingly, two subsamples were selected to further investigate the performances of the volatility of the iron ore spot price before and after the change in the forward pricing mechanism.

\subsection{Modelling Iron Ore Spot Price Volatility}

To estimate the volatility of the iron ore spot price return over different subsample periods, we used an exponential GARCH (EGARCH) model. The EGARCH model firstly introduced by Nelson (1991) is parametrically designed to model a nonlinear variance clustering (heteroskedasticity) in the time series sample. If the conditional heteroskedasticity exists in the sample period, the mean and variance equation of the $\operatorname{EGARCH}(1,1)^{4}$ model can be specified as follows:

$$
\begin{aligned}
& r_{t}=\delta_{0}+\sum_{i=1}^{p} \delta_{i} r_{t-i}+\varepsilon_{t}, \varepsilon_{t} \sim\left(0, \sigma_{t}^{2}\right) \\
& \log \left(\sigma_{t}^{2}\right)=\omega+\beta \log \left(\sigma_{t-1}^{2}\right)+\alpha\left|\frac{\varepsilon_{t-1}}{\sigma_{t-1}}\right|+\gamma \frac{\varepsilon_{t-1}}{\sigma_{t-1}}
\end{aligned}
$$

In the mean equation of (4), $r_{t}$ is a function of past price return $r_{t-1}, \varepsilon_{t}$ denotes the white noise with the normal distribution, and $p$ is the number of lagged price returns. Likewise, in the variance equation, $\omega$ represents the deterministic term and is assumed to be positive. The log of GARCH term $\sigma_{t}^{2}$ allows that the coefficients in the variance equation can be negative.

The EGARCH model has several advantages for estimating price volatility, compared to other GARCH models. Firstly, in contrast to other GARCH models, the EGARCH model has no restrictions on the coefficients $(\omega, \beta, \gamma, \alpha)$. Secondly, the coefficient $\beta$ is the parameter of long memory measuring the persistent impact of a positive or negative shock on the conditional variance. The persistence of a shock effect on the price variance may be long or short and depends on the absolute value $\beta$. The closer the value $\beta$ approximates to one, the longer the shock to the conditional variance may persist. Thirdly, the EGARCH model provides a plausible approach to investigate the asymmetric effect on price volatility which is represented by the coefficient $\gamma$. If $\gamma<0$, the negative shocks result in higher price volatility than the positive shocks, and vice versa. There is no asymmetric effect if $\gamma=0$. Fourthly, by constructing the relationship between $\sigma_{t}$ and $\varepsilon_{t-1}$ in the EGARCH model, we can illustrate the impact of positive or negative shocks (good or bad news) on price volatility. The derived graphic curve is defined as the news impact curve (Engle and $\mathrm{Ng}$, 1993), which is characterized as follows:

$$
\begin{array}{ll}
\sigma_{t}=\Omega \cdot \exp \left[\frac{(\gamma+\alpha)}{\sigma} \cdot \varepsilon_{t-1}\right], & \varepsilon_{t-1}>0 \\
\sigma_{t}=\Omega \cdot \exp \left[\frac{(\gamma-\alpha)}{\sigma} \cdot \varepsilon_{t-1}\right], & \varepsilon_{t-1}<0
\end{array}
$$

As expressed in equation (5), the news impact curve is an exponential function where its value is exponentially increasing in both directions $\left(\varepsilon_{t-1}>0\right.$ stands for positive shock, and vice versa).

\footnotetext{
${ }^{4}$ The EGARCH $(1,1)$ model is frequently used from the family of the EGARCH $(p, q)$ models. The $p$ in the parenthesis of the EGARCH $(p, q)$ means the number of coefficient $\alpha$, while the $q$ means the number of coefficient $\beta$.
} 
The news impact curve graphically describes the asymmetric effect on price volatility. Furthermore, the magnitude of the impact of a shock on price volatility depends on the slope of the news impact curve.

\section{Empirical Analysis}

This section examines the impact of the change in the forward pricing mechanism on the volatility of the iron ore spot price. Firstly, the observed data series is separated into two subsamples in terms of the date of the change in the forward pricing mechanism, which is supported by the result of the structural break. Then, the volatility of the iron ore spot price for the different subsample periods is estimated and is compared by using the $\operatorname{EGARCH}(1,1)$ models.
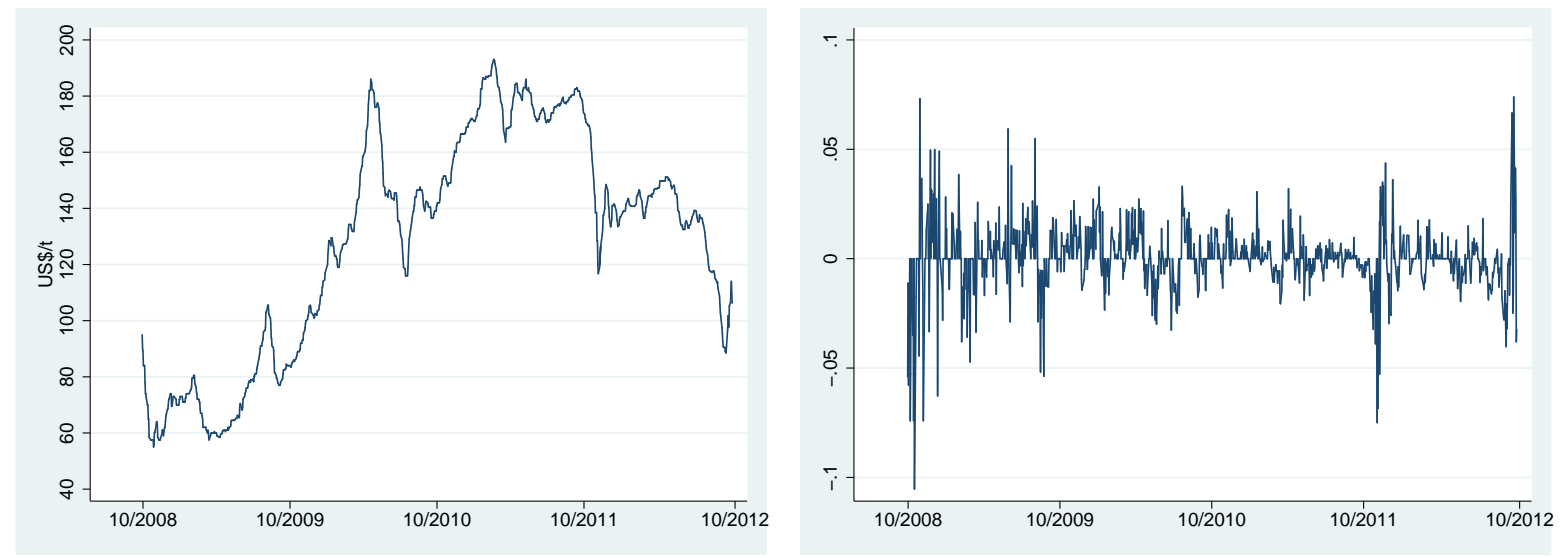

Figure 1: Iron ore spot price series (62\% Fe, CFR China) and return series Source: Graphed using data from Platts IODEX (2012), and Author's Calculation.

\subsection{Data and Test of Structural Break}

Data of the daily iron ore spot price was exclusively collected from the Platts IODEX over the period October 7, 2008 to September 21, 2012. Since these data may behave unstably, we used the logarithm of the iron ore spot price expressed in equation (1) to compute the return series ${ }^{5}$. This data is plotted in Figure 1. The stationary return series is also confirmed by the second column in Table 2, where the ADF statistic of return series is significant at a $1 \%$ level.

To determine the date of the structural break caused by the change in the iron ore forward pricing mechanism, we applied the ICSS algorithm to the return of the iron ore spot price. Consequently, several important dates of structural breaks were obtained, and these are summarized in Table 1. These discovered break dates are linked closely with some major economic or noneconomic events in the global iron ore market. As observed in Table 1, these break dates do not synchronize with the exact time of the occurrence of major events. Thus, the volatility of the iron ore spot price return may not align with the shocks of different major events. For example, price

\footnotetext{
${ }^{5}$ Iron ore spot price return replaces the role of spot price, and is the center for further analysis.
} 
volatility seems to slowly react to the global financial crisis and other economic crises, while it may quickly react to the change in the forward pricing mechanism. Therefore, this study suggests that the most relevant date for the change in the forward pricing mechanism is March 10, 2010.

Table 1: Summary of the result of the structural break

\begin{tabular}{lll}
\hline Break Dates & Major Relevant Events \\
\hline Return Series of the Iron Ore Price $\left(r_{t}\right)$ & $\begin{array}{c}\text { December 22, 2008 } \\
\text { March 10, 2010 }\end{array}$ & The global financial crisis \\
& The switch in the iron ore forward pricing mechanism \\
& The Aust 6, 2010 & $\begin{array}{l}\text { The Aulian government proposed the new Minerals } \\
\text { Resource Rent Tax }\end{array}$ \\
& October 7, 2011 & The European sovereign-debt crisis \\
\hline
\end{tabular}

Notes: The results indicate several structural breaks for the full sample period (from October 8, 2008 to September 21,2012 ) of the return of the iron ore spot price, based on the algorithm of the ICSS (Inclan and Tiao, 1994).

After determining the relevant date for the change in the forward pricing mechanism (March 10, 2010), we split the spot price series into the two subsamples (October 8, $2008^{6} \sim$ March 9, 2010 and March 10, 2010 September 21, 2012) and derived some descriptive statistics (see Table 2). The high values of skewness, kurtosis and Jarque-Bera for the two subsample periods show that they may have sharper peaks and heavier tails than normal distributions. However, the daily average return over the two subsample periods declines from $0.0929 \%$ to $-0.0338 \%$. Concurrently, the unconditional standard deviation in the return series also experiences a fall from $1.876 \%$ to $1.227 \%$ over the two periods. These identified declines in the unconditional variance may provide preliminarily support for the view that the implementation of the quarterly pricing mechanism curbs the high volatility of the iron ore spot price.

Table 2: Descriptive statistics of sample data

\begin{tabular}{lrrrr}
\hline & $\mathbf{P}_{\mathbf{t}}$ & $\mathbf{r}_{\mathbf{t}}$ & $\mathbf{r}_{\mathbf{t} 1}$ & $\mathbf{r}_{\mathbf{t} 2}$ \\
\hline Mean & 128.312 & 0.000113 & 0.000929 & -0.000338 \\
Median & 137 & 0 & 0 & 0 \\
Maximum & 193 & 0.073925 & 0.073151 & 0.073925 \\
Minimum & 55 & -0.10536 & -0.10536 & -0.074941 \\
Std. Dev. & 39.9585 & 0.014912 & 0.018759 & 0.01227 \\
Skewness & -0.3134 & -0.70828 & -1.13102 & 0.108304 \\
Kurtosis & 1.8523 & 11.114 & 9.118616 & 10.7735 \\
Jarque-Bera & 70.4642 & 2792.705 & 624.1298 & 1602.567 \\
Obs. & 989 & 988 & 352 & 636 \\
ADF Statistic & -1.5726 & $-10.0431^{* * *}$ & $-6.3749^{* * *}$ & $-7.6840^{* * *}$ \\
\hline
\end{tabular}

Notes: The result of the ADF unit root test is based on the test of random walk and no time trend with four lagged differences. ${ }^{* * *}$ refers to significance at the $1 \%$ level.

In terms of the dynamics of the return of the iron ore spot price in Figure 1, volatility clustering is strong and evident. In addition, using the Ljung-Box and Engle (1982) LM ARCH test on

\footnotetext{
${ }^{6}$ The data for October 7, 2008 is dropped due to the computation of return series.
} 
the two subsamples, we found evidence of autoregressive conditional heteroskedasticity (ARCH effect) in iron ore spot prices. Therefore, the unstable behavior of the iron ore spot prices for the different sample periods support the EGARCH $(1,1)$ models as perhaps providing significant estimations to the conditional variance.

\section{2. $\operatorname{EGARCH}(1,1)$ Model}

This section uses the EGARCH $(1,1)$ model to estimate and to compare the conditional variance of the return of the iron ore spot price for the full sample period $\left(r_{t}\right)$ and the two subsample periods $\left(r_{t 1}, r_{t 2}\right)$. The estimation starts with the construction of the mean and variance equation to measure the average return and the conditional variance of the iron ore price for the different sample periods. Then these values of conditional variance need to be compared, and associated with the analysis of the long memory, the asymmetric effect and the news impact curve.

Table 3: Estimates of the EGARCH(1,1) models for the volatility of the daily iron ore spot price return.

$\mathbf{r}_{\mathbf{t}} \quad \mathbf{r}_{\mathbf{t} 1} \quad \mathbf{r}_{\mathbf{t} 2}$

$\mathbf{r}_{\mathbf{t} 2}$

Full Sample Period Oct.8,2008-Mar.9,2010 Mar.10,2012-Sep.21,2012

\begin{tabular}{|c|c|c|c|}
\hline Mean Equation & $r_{T}=$ & ${ }_{T-i}+\varepsilon_{T}, \varepsilon_{T} \sim\left(0, \sigma_{T}^{2}\right)$ & $T=t, t 1, t 2$ \\
\hline \multicolumn{4}{|c|}{ Variance Equation } \\
\hline$\omega$ & $\begin{array}{c}-0.5693^{* * *} \\
(0.0810)\end{array}$ & $\begin{array}{c}-1.5766^{* * *} \\
(0.3245)\end{array}$ & $\begin{array}{r}-0.5620^{* * * *} \\
(0.1123)\end{array}$ \\
\hline$\beta$ & $\begin{array}{c}0.9616^{* * *} \\
(0.0075)\end{array}$ & $\begin{array}{c}0.8540^{* * *} \\
(0.0367)\end{array}$ & $\begin{array}{c}0.9614^{* * *} \\
(0.0103)\end{array}$ \\
\hline$\alpha$ & $\begin{array}{c}0.3074^{* * *} \\
(0.0258)\end{array}$ & $\begin{array}{c}0.4513^{* * *} \\
(0.0969)\end{array}$ & $\begin{array}{c}0.2786^{* * *} \\
(0.0271)\end{array}$ \\
\hline$\gamma$ & $\begin{array}{c}-0.0744^{* * *} \\
(0.0192)\end{array}$ & $\begin{array}{c}-0.3420^{* * *} \\
(0.0709)\end{array}$ & $\begin{array}{c}-0.0956^{* * *} \\
(0.0198) \\
\end{array}$ \\
\hline \multicolumn{4}{|l|}{ Diagnostics } \\
\hline AIC & -6.3430 & -5.6273 & -6.7603 \\
\hline SIC & -6.2882 & -5.5050 & -6.6826 \\
\hline Log Likelihood & 3125.409 & 984.515 & 2140.485 \\
\hline $\mathbf{Q}(\mathbf{5})$ & 2.3231 & 5.4019 & 1.2980 \\
\hline $\begin{array}{l}\text { LM Test(1) } \\
\text { F-test }\end{array}$ & 0.3442 & 1.1755 & 0.0184 \\
\hline $\mathbf{n R}^{2}$ & 0.3448 & 1.1783 & 0.0185 \\
\hline
\end{tabular}

In order to find the best fit $\operatorname{EGARCH}(1,1)$ model, the best fit mean and variance equation is 
required for the autoregressive return of the iron ore spot price. The best fit results are reported in Table 3. As shown, six lagged variables are applied to all the mean equations to remove the disturbance of autocorrelation. Under the mean equations, the white noises of residuals $\left(\varepsilon_{T} \sim\left(0, \sigma_{T}^{2}\right)\right)$ indicating the problem of pre-estimated non-normality for all the sample periods is addressed. Simultaneously, in the variance equations, the significant coefficients (at the $1 \%$ level) suggest that the EGARCH $(1,1)$ models successfully capture the time varying patterns of the conditional variance of the returns of the iron ore spot price for the different sample periods.

Correspondingly, all the diagnostic tests in Table 3 are robust for checking whether or not the selected EGARCH $(1,1)$ models are best fit for all the sample periods. The comparatively low values of AIC and SIC and the large values of log likelihood provide evidence that the selected EGARCH $(1,1)$ models are best fit. Moreover, the results of Q statistics suggest that the null hypothesis that there is no pattern of serial correlation in the model residuals cannot be rejected. This judgment is also valid for the results of ARCH LM tests; there are no remaining ARCH effects in the residuals.

Next, we proceed to discuss the characteristics of coefficients in the variance equation for the full sample period (Table 3). In particular, for the full sample period the value of long memory parameter $\beta$ reaches 0.9616 , which is close to one. This finding indicates that the shocks (positive or negative) to conditional variance may die out slowly. This also shows that shocks may have a permanent effect on the volatility of the iron ore price. Simultaneously, the value of coefficient $\gamma$ is -0.0744 , which stands for the asymmetric effect on iron ore spot price for the full sample period. This negative value of $\gamma$ suggests that the negative shocks to the iron ore spot price give rise to more volatility than the positive shocks do.

For two subsample periods (October 8, 2008 March 9, 2010 and March 10, 2010 September $21,2012)$, the long memory and the asymmetric effect are fairly similar to the full sample period. However, the trend of the conditional variance appears to be different after the break date (March 10,2010 ). More specifically, the value of $\beta$ slightly increases from 0.8540 to 0.9614 , implying that the shocks to conditional variance appear to decay at a comparatively slower rate after the break date than before the break date. Thus, the high volatility of the iron ore spot price subject to such shocks may not disappear after the change in the forward pricing mechanism. Meanwhile, the value of $\gamma$ increases from -0.3420 (before the break date) to -0.0956 (after the break date). This value is near zero after the break date, suggesting that the asymmetric effect on conditional variance is relatively weaker than that before the break date. Thus, the ability of negative shocks to induce the volatility of the iron ore spot price seems to diminish after the change in the forward pricing mechanism.

The results in Table 3 show that the long memory of shocks in price volatility seems to be sustained after the change in the forward pricing mechanism. However, relating such change to the asymmetric effect on the volatility of the iron ore spot price we find this effect may turn out to be less strong. Furthermore, in terms of the residuals for the two subsample periods $\left(\varepsilon_{T}\right)$, the news impact curve is properly drawn to graphically check the asymmetric effect on the volatility of the iron ore spot price.

As depicted in the left-hand side of Figure 2, the news impact curve for the period before the change in the forward pricing mechanism is steeper than that after the pricing change. On the contrary, on the right-hand side, the two curves are moving around zero. Therefore, the news 


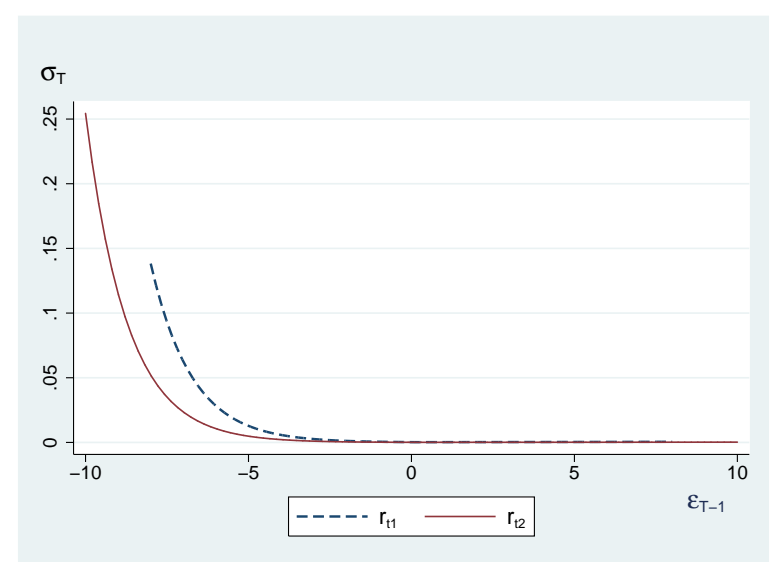

Figure 2: News impact curve of iron ore spot price return for two subsamples

impact curves in Figure 2 demonstrate that the iron ore spot price is highly sensitive to the negative shocks (bad news), while the positive shocks (good news) seemingly have no impact on the volatility of the iron ore spot prices. More specifically, as revealed by the slopes of curves, the asymmetric effect on the volatility of the iron ore price is weaker after the change in the forward pricing mechanism. This finding is consistent with the indication of $\gamma$ over the two subsample periods.

Table 4: Descriptive statistics of the conditional variance series for two subsamples

\begin{tabular}{lrrrrrr}
\hline & Mean & Median & Maximum & Minimum & Std. Dev. & Obs. \\
\hline Conditional variance of $\mathbf{r}_{\mathbf{t 1}}$ & 0.000318 & 0.000158 & 0.004619 & 0.000050 & 0.000489 & 346 \\
Conditional variance of $\mathbf{r}_{\mathbf{t} 2}$ & 0.000098 & 0.000063 & 0.001152 & 0.000011 & 0.000133 & 630 \\
\hline
\end{tabular}

In addition, the dynamics of the conditional variance series computed by the EGARCH (1, 1) models for the two subsample periods may provide another tool to examine the impact of the change in the forward pricing mechanism on the volatility of the iron ore spot price. Table 4 presents the descriptive statistics for the values of conditional variance based on two subsample periods. As shown, the mean conditional variance decreases from $0.0318 \%$ to $0.0098 \%$ after the pricing change. The mean conditional variance is also the key value for judging the tendency of price volatility. Combined with the findings in both the unconditional variance and the conditional variance, we find that the iron ore spot prices may be less volatile after the pricing change. This finding seems to be confirmed by Figure 3, where the number of striking spikes in the conditional variance tends to be less after the pricing change.

To summarize, after the change in the forward pricing mechanism, there seems to be a diminishing trend in both the unconditional variance and the conditional variance of the iron ore spot price. Except for the slight increase in the long memory, the asymmetric effect on the volatility of the iron ore spot price may be dampened after the pricing change. This diminishing effect is also evident in the mean of the conditional variance series. 

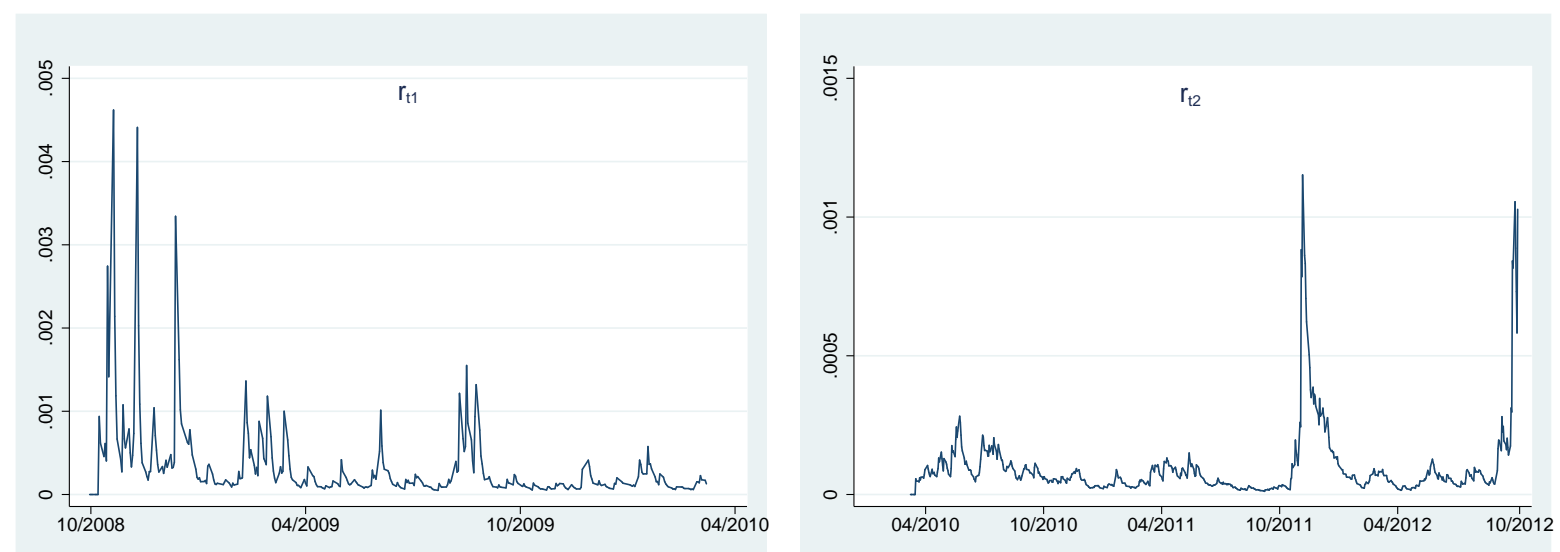

Figure 3: Conditional variance series for two subsamples

Empirical evidence may have implications for the iron ore market participants and the policy makers. Firstly, to hedge against the high volatility of the iron ore spot price, the "Big Three" introduced the quarterly forward pricing mechanism. Our evidence suggests this new forward pricing mechanism may be an effective strategy to reduce the volatility of the iron ore price, and to consequently mitigate market uncertainty. Secondly, although the new forward pricing mechanism seems to be useful for reducing volatility of the spot price, the impact of negative shocks on volatility may not be ignored. Our results find that the negative shocks rather than the positive shocks have an effect on the volatility of the iron ore spot price after the change in the forward pricing mechanism.

\section{Conclusion}

Examining the impact of the change in the forward pricing mechanism on the volatility of the iron ore spot price is important for both the market participants and the policy makers. The results of this study show that the implementation of the quarterly pricing mechanism seems to alleviate the volatility of the iron ore spot price. In the light of the empirical procedures applied to the two subsample periods, a significant decrease is found in both unconditional variance and conditional variance. Especially for the conditional variance, although the long memory of shock is remained the asymmetric effect on the volatility of the iron ore spot price is weakened. The weakening asymmetric effect conforms to evidence of the news impact curve. More importantly, the news impact curve suggests that only the negative shocks have a gradual effect on the volatility of the iron ore spot price. In this sense, the high volatility of the iron ore spot price is expected when the negative shocks are present. These results may have implications for the iron ore market participants and the policy makers in their attempts to minimize price volatility and market uncertainty. It is noticeable that the volatility of the iron ore spot price may not immediately correspond to the market shocks. The lag factor in the iron ore spot price is worth future study. 


\section{References}

Arouri, M. E. H., Lahiani, A., Lévy, A., Nguyen, D. K., 2011. Forecasting the conditional volatility of oil spot and futures prices with structural breaks and long memory models. Energy Economics 34 (1), 283-293.

Bhattacharyya, S., Deepak, P., 2012. Comprehending the changing global iron ore trade service system and the dynamics of pricing. International Journal of Business and Globalisation 9 (1), 70-89.

Bollerslev, T., 1986. Generalized autoregressive conditional heteroskedasticity. Journal of econometrics 31 (3), 307327.

Caporale, T., McKiernan, B., 1997. High and variable inflation: Further evidence on the friedman hypothesis. Economics Letters 54 (1), 65-68.

Convey, K., 2012. Iron ore mining in australia. Los Angeles-based industry research firm IBISWorld.

Crowson, P., Maxwell, P., Guj, P., 2006. Mineral markets, prices and the recent performance of the minerals and energy sector. Australian Mineral Economics.

Engle, R. F., 1982. Autoregressive conditional heteroscedasticity with estimates of the variance of united kingdom inflation. Econometrica: Journal of the Econometric Society, 987-1007.

Engle, R. F., 1983. Estimates of the variance of us inflation based upon the arch model. Journal of Money, Credit and Banking 15 (3), 286-301.

Engle, R. F., Ng, V. K., 1993. Measuring and testing the impact of news on volatility. The journal of finance 48 (5), 1749-1778.

Hammoudeh, S., Yuan, Y., 2008. Metal volatility in presence of oil and interest rate shocks. Energy Economics 30 (2), 606-620.

Inclan, C., Tiao, G. C., 1994. Use of cumulative sums of squares for retrospective detection of changes of variance. Journal of the American Statistical Association 89 (427), 913-923.

Musacchio, A., Khanna, T., Bernhardson, J., 2010. In the spotlight: The market for iron ore. Harvard Business School.

Narayan, P. K., Narayan, S., 2007. Modelling oil price volatility. Energy Policy 35 (12), 6549-6553.

Narayan, P. K., Popp, S., 2010. A new unit root test with two structural breaks in level and slope at unknown time. Journal of Applied Statistics 37 (9), 1425-1438.

Nelson, D. B., 1991. Conditional heteroskedasticity in asset returns: A new approach. Econometrica: Journal of the Econometric Society, 347-370.

Platts, 2012. Platts daily iron ore price. Platts Offices.

Salisu, A. A., Fasanya, I. O., 2012. Modelling oil price volatility with structural breaks. Energy Policy 52 (1), $554-$ 562.

UNCTAD, 2010. The iron ore market, 2009-2011. United Nations Conference on Trade and Development.

Wilson, J. D., 2012. Chinese resource security policies and the restructuring of the asia-pacific iron ore market. Resources Policy 37 (3), 331 - 339. 